Twelve chapters deal with a variety of scientific disciplines into which the authors themselves have extended their investigations. The introductory article on postnatal enzymatic adaptation discusses the factors that influence the start of enzyme activity at various stages before or after birth and thus provides the framework for the other contributions. It is rightly pointed out that biologically active proteins are the substrate of adaptation, and that disturbances of their synthesis may lead to grave disturbances of an infant's health. Logically then follow discussions on protein synthesis in the pre- and postnatal period, on maturation of the immunoglobulins, on antigen tolerance, and sensitization in the perinatal phase. Special attention is also paid to the development of the blood coagulation system, the mechanism of fat absorption, temperature regulation in the newborn, oxygen and $\mathrm{CO}_{2}$ exchange in the human placenta, and to the factors influencing muscle tone during infancy.

This is an extremely valuable book for paediatricians interested in a better understanding of the developing human body and who want to base their activities on a sound knowledge of its physiology. It might be an eyeopener to those who so far have failed to grasp the particular biological problems of growth.

The print is pleasing, and the diagrams are helpful and clearly drawn. The text as well as the references, including those in French and English, are singularly free of printing errors.

The book is a credit to editor and publisher alike.

\section{Disorders of Carbohydrate Metabolism in Infancy.}

By Marvin CoRnblath and Robert Schwartz. (Volume III in the Series Major Problems in Clinical Pediatrics. Alexander J. Schaffer Consulting Editor) (Pp. xiv +297 ; 68 figures +23 tables. 59s. 6d.) Philadelphia and London: W. B. Saunders. 1966. In this book, the third of a series, Major Problems in Pediatrics, the authors have, in their own words 'attempted to present our own current concepts of the normal and abnormal physiology of carbohydrate metabolism in the fœtus, the pregnant mother, the neonate and the infant'. Part I surveys metabolism of carbohydrate, the metabolic adjustments in pregnancy and in the neonate both fullterm and low birthweight; Part II, present knowledge and thinking on the infant of the diabetic mother and on transient neonatal hypoglycaemia and transient diabetes mellitus in early infants; Part III, disorders of glycogen metabolism, and hereditary galactose and fructose intolerance (what in this country would be called galactosaemia and fructosaemia).

This is a gigantic task and, one might think, an almost impossible one to achieve within the compass of 280 pages, and indeed the reviewer rapidly suffered reader's indigestion. This is particuarly so in the biochemical sections, where the compression is such that it is almost useless to anyone except those who already have a full understanding of the subject. Nevertheless, the book gives a very comprehensive review of the biochemistry, genetics, and clinical aspects of a whole range of conditions mentioned. There are many diagrams, some of which are helpful, and for good measure there are two appendices, the first on diets for disorders of carbohydrate metabolism and the second on carbohydrate content of a very large range of foods.

Perhaps the book's most useful function is for quick reference and for the references it contains to the literature, which are considerable and up-to-date. As usual with American books, production, printing, and paper are of high quality.

Neue Aspekte der Kinderchirurgie. Edited by $\mathbf{M}$. Bettex. (Postgraduate Courses in Pediatrics 17). (Pp. 93; 55 figures +7 tables. sFr/DM. 20.) Basel and New York: S. Karger. 1966.

This slim volume of 90 pages is No. 17 in a series of postgraduate courses in paediatrics, published over the past 4 years by the University Clinic in Berne, Switzerland. Three of the contributions come from the paediatric surgical clinic in Berne. Bettex, who edits this volume, reviews the present status of surgery for cleft lip and palate with a welcome clarity of presentation.

Kuffer and Duc analyse the surgical causes of acute respiratory difficulty, especially the tension lesions in the chest. Sharli's chapter on the oesophagus and cardia includes a review of their small but good series of results in oesophageal atresia, and presents a large series of fundal plications for hiatus hernia.

Nicole of Basel reports on craniosynostosis (having operated on more than half of the 108 cases seen in the past 10 years): this is a useful study of the correlation between clinical, radiological, operative, and histological criteria of craniostenosis.

Grob of Zürich presents the current practice of early active surgical treatment of myelomeningocele and hydrocephalus, and supports this view from his own modest series.

Duhamel, making the only contribution in French to this collection of surgical papers in German, clarifies the syndrome of functional obstruction of the colon without aganglionosis in infancy, and also reports on his experience of sphincterectomy for anorectal achalasia, with good results but varied histological findings.

As a group of essays on a few aspects of current paediatric surgical practice, the book is a useful addition to the series.

Pseudohypoparathyreoidismus und PseudoPseudohypoparathyreoidismus. Hereditärer brachymetacarpaler Kleinwuchs. By GERHARD Schwarz. (Experimentelle Medizin, Pathologie und Klinik: Band 15.) (Pp. viii $+140 ; 37$ figures +5 tables. DM. 32.) Berlin, Göttingen, Heidelberg, New York: Springer-Verlag. 1964.

This is the 15th monograph in the series 'Experimenttelle Medizin, Pathologie und Klinik' and adds another well-produced, well-written review of a subject that 